\title{
Proposed cross-linking model for carboxymethyl cellulose /starch superabsorbent polymer blend
}

\author{
Auda Jabbar Braihi ${ }^{1}$, Sihama Issa Salih ${ }^{2}$, Fadhel Abbas Hashem ${ }^{2}$, Jaleel Kareem Ahmed ${ }^{1}$ \\ ${ }^{1}$ Babylon University- College of Materials Engineering, Polymer and Petrochemical Industries Department, Babylon, Iraq \\ ${ }^{2}$ University of Technology-Materials Engineering Department, Baghdad, Iraq
}

\section{Email address:}

auda_1964@yahoo.com(A. J. Braihi), sihama_salih@yahoo.com(S. I. Salih), hashembsb@yahoo.com(F. A. Hashem), jaleel_karim@yahoo.com(J. K. Ahmed)

\section{To cite this article:}

Auda Jabbar Braihi, Sihama Issa Salih, Fadhel Abbas Hashem, Jaleel Kareem Ahmed. Proposed Cross-Linking Model for Carboxymethyl Cellulose /Starch Superabsorbent Polymer Blend. International Journal of Materials Science and Applications.

Vol. 3, No. 6, 2014, pp. 363-369. doi: 10.11648/j.ijmsa.20140306.23

\begin{abstract}
Superabsorbent polymer (SAP) blend has been synthesized from Carboxymethyl Cellulose (CMC) , starch, and aluminum sulfate octadecahydrate cross-linker. Water Absorption Capacity (WAC), FTIR, SEM, DSC, CHO, Flame Photometer and ignition tests are carried out to determine the used CMC formula, investigate the cross-linking process, and suggest a cross-linking model. Flame Photometer results showed there are two sodium acetate groups in the CMC molecule. This result confirmed by theoretical calculations and $\mathrm{CHO}$ test. To investigate which of $\mathrm{Al}^{3+}$ and $\mathrm{SO}_{4}{ }^{2-}$ ions causes the crosslinking : the extraction of the cross-linked $\mathrm{CMC} /$ starch tested with $\mathrm{BaCl}_{2}$ solution(showed dense white precipitate ; sulfate group not share for blend formation), $\mathrm{NaOH}$ solution( showed white precipitate of aluminum hydroxide; $\mathrm{Al}^{3+}$ ion present (i.e. $\mathrm{Al}^{3+}$ ion share in the blend structure). These results confirmed by flame test for sodium ion, which showed high Na emission energy (5.75); there is an exchange between $\mathrm{Al}$ and $\mathrm{Na}$ ions. To check that aluminum is a part of the structure, sample of the cross-linked CMC ignited. A white precipitate appear for aluminum oxide, which confirms the presence of Al. Based on that there are three $\mathrm{CMC}$ molecules connected to each $\mathrm{Al}$ atom, theoretical calculations about the amount of $\mathrm{Al}$ in the cross-linked $\mathrm{CMC}$ molecule showed a good agreement with the $\mathrm{CHO}$ results (5.613\% Vs. $5.739 \%$ respectively). FTIR spectrum of the cross-linked $\mathrm{CMC} /$ starch blend showed that there is a reaction between $\mathrm{CMC}$ and starch molecules; i.e. the new repeating unit contains three starch molecules. This conclusion confirmed by theoretical calculations and results of EDX, CHO, and ignition tests. $\mathrm{Al} \%$ in the new mer appeared a good agreement between theoretical calculations (4.32\%) and $\mathrm{CHO}$ results (4.512\%). Ignition test calculations confirmed that the new mer contains three Al atoms. Evidences of the occurrence of the cross-linking process were obtained from FTIR, morphology, DSC and absorbency results. Absence of the primary hydroxyl alcohol band in the $\mathrm{CMC} /$ starch blend spectrum, indicates that this site is active and the reaction between starch and CMC molecules occurs through it. Morphologies studies showed that the sample after crosslinking is more compact than before as well as show one piece for after cross-linking comparing with different pieces before cross-linking.Optimum cross-linking ratio appeared to be $2 \mathrm{wt} \%$ corresponded to WAC equal to $58 \mathrm{~g} / \mathrm{g}$.in distilled water and DSC results indicates that CMC/starch is a miscible blend.
\end{abstract}

Keywords: Superabsorbent Polymer, Cross-Linking, NaCMC

\section{Introduction}

Superabsorbent polymers (SAPs) are one of the most fascinating materials in modern polymer technology. These polymers are able to absorb up to $1500 \mathrm{~g}$ of water per gram of SAP [1].SAPs containing absorbed liquid are called a hydrogels[2].

The swelling properties of these hydrogels have attracted the attention of researchers and technologists, and have found wide-spread applications in drug delivery systems, agriculture, separation processes and many other fields [3].

Generally they consist of a network of polymer chains that are cross-linked to avoid dissolution. Usually there are ionic functional groups along the polymer chains to encourage diffusion of water within the network.[4]. 


\section{Crosslinking Process}

Cross-links between polymer chains form a threedimensional network and prevent the polymer swelling to infinity i.e. dissolving. Cross-linking makes SAPs insoluble in water [5].

This is due to the elastic retraction forces of the network, and is accompanied by a decrease in entropy of the chains, as they become stiffer from their originally coiled state[6].

Crosslinks can be formed by covalent, electrostatic, or hydrophobic bonds, or dipole-dipole interactions [7].

Small amounts of cross-linkers play a major role in modifying the properties of superabsorbent polymers. In addition to modifying the swelling and mechanical properties, the cross-linker affects the amount of soluble polymer found during the polymerization. Efficiency of crosslinking will also depend on steric hindrance and reduced mobility at the site of pendant double bonds, the tendency of a given crosslinker to undergo intermolecular addition reactions, and the solubility of the cross-linker in the monomer mixture[8].

The cross-linking agent, is a monomer with two or more double bonds, decrease the molecular freedom by joining polymer chains together through covalent or ionic bonds to form three-dimensional network. It is network allows liquid absorption into the empty spaces between the polymer chains and prevents the polymer to dissolve due to the elastic retraction forces of the network. The degree of cross-linking increases the strength of the network (gel strength) [9].

Covalent crosslinks are formed when the major monomers (e.g., acrylic acid) is copolymerized with a di-,tri-, or tetra vinyl monomer such as N,N-methylenebis(acrylamide). Ionic cross-links are formed by reacting a polyvalent ion of opposite charge with the charged polymer chains. The crosslink forms as a result of charge association of the unlike charges.

Physical crosslink usually formed by means of hydrogen bonding of segments of one chain with the segments of another chain.

\section{Crosslinking Types in Superabsorbent Polymers (SAPs)}

There are two main types of cross-linking in most SAPs:

\subsection{Bulk or Core Crosslinking}

Normally takes place during the polymerization stage of superabsorbent production. In SAP manufacture the most common types of cross-linker are organic molecule that contain two or more polymerizable double bonds. These molecules are incorporated into the backbone of the polymer chains as they grow during the polymerization reaction.

Reactivity ratios are a measure of the affinity for each of the reaction components to react with each other, i.e. does an acrylic acid molecule prefer to react with one like itself or something else like a cross-linker molecule for example [6].

If the cross-linker has a high reactivity ratio then most of it will be consumed in the early stages of the polymerization and any polymer chains made during the latter stages will be less likely to cross-link and end up as extractable chains.

Cross-linkers with low reactivity ratios have the opposite tendency. The choice of cross-linker or mixture of crosslinkers determines the structure of the final polymer network.

Generally, low molecular weight polymer chains, that are not incorporated into the polymer network are called the soluble or extractable fraction. The degree of soluble polymer is important in determining the optimum cross-linker level and performance of the product. Too little cross-linker and the polymer will have a high swelling capacity, low strength against pressure and a tacky feel due to high extractable, and too much will give low extractable, low tackiness but a low swelling capacity.

\subsection{Surface Crosslinking}

Improving the absorption against pressure and the swelling rate of a SAP can be achieved by cross-linking the surface of the particles. Post cross-linking is normally performed on the dried, milled and sized SAP as the final stage of the process.

Surface cross-linking of the superabsorbent particles improves the flow significantly. The surface-cross-linked particles maintain their shape during the swelling process, which generates a less densely packed gel bed with air pockets, so the fluid can flow in a less restricted fashion (Figure 1, b). This higher permeability allows for a more efficient use of the gel bed[10].

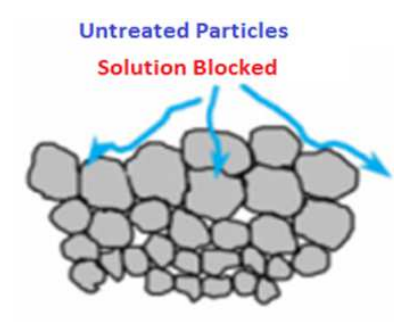

Uncontrolled Swelling / Gel Blocking

a

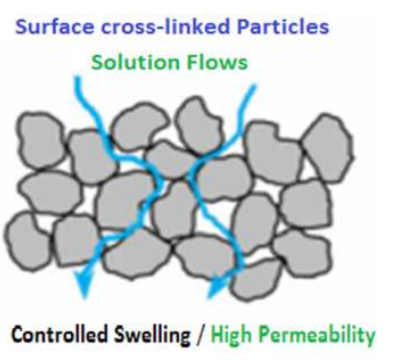

b
Fig.(1). Schematic representation of the swelling and flow of aqueous solutions through the (a) uncross-linked and (b) surface-cross-linked SAP particles in the gel bed[10]

\section{Experimental Part}

\subsection{Materials}

Carboxymethyl Cellulose Sodium Salt NaCMC and corn $\operatorname{starch}(25 \%$ amylose and $75 \%$ amylopectin) were obtained from HIMMEDIA Laboratories Pvt. Ltd. Company (India) . Pure Aluminum Sulfate Octadecahydrate $\mathrm{Al}_{2}\left(\mathrm{SO}_{4}\right)_{3} \cdot 18 \mathrm{H}_{2} \mathrm{O}$ was obtained from REACHIM Company (USA).

\subsection{Preparation of the Cross-Linked CMC}

An appropriate amount of CMC solution agitated for 1 hour at $70^{\circ} \mathrm{C}$. Aluminum sulfate octadecahydratecross-linker was added and allowed to mix for another 30 minutes. The solution was then spread on Teflon baking pans and dried 
at $70^{\circ} \mathrm{C}$ ( in a WG 71 Electric Blast Dry Box) until a film is formed. The film was shredded with a blender, then ground into a powder with a mortar and pestle.

\subsection{Preparation of the Cross-Linked CMC/Starch Blend}

The cross-linked CMC/ starch blend prepared as follows: An appropriate amount of starch dissolved in distilled water (DW) in water bath $80^{\circ} \mathrm{C}$ for 45 minute. Dried film of the cross-linked CMC, was crushed and dissolved in DW. Using magnetic hot plate, gelatinized starch (step1) mixed with the solution obtained from step 2 for 30 minute at $70^{\circ} \mathrm{C}$. Result paste was dried overnight at $100^{\circ} \mathrm{C}$, crushed, and tested.

\subsection{Tests}

\subsubsection{Water Absorption Capacity (WAC)}

WAC wasmeasured using tea-bag method according to the following equation :

$$
W A C=\frac{W I-W 0}{W o}
$$

Where $\mathrm{W}_{0}$ : dry weight and $\mathrm{W}_{1}$ wet weight

\subsubsection{Structural Analysis}

Infrared spectra of the SAPs in $\mathrm{KBr}$ pellets(mass ratio of 1:10) were obtained from $4000-400 \mathrm{~cm}^{-1}$ using IR Affinity1 SHIMADZU Fourier Transform Infrared Spectrometer Class 1 laser product.

Analytical Scanning Electron Microscope (SEM), model (Tescan VEGA-SB)used to examine the surface morphology of gels, which is first sputtered with gold .

To measure $\mathrm{T}_{\mathrm{g}}$, differential scanning calorimetry (DSC), type ETTLER TOLEDO (Switzerland), model DSC1 was used with $\mathrm{STAR}^{*} \mathrm{E}$ software, test conditions (Temperature range: $25-300^{\circ} \mathrm{C}$, Heating rate: $10 \mathrm{~K} / \mathrm{min}, \mathrm{N}_{2}$ gas $50 \mathrm{ml} / \mathrm{min}$ ).

\subsubsection{CHO Test \\ EURO EA Elemental Analyzer, EURO Vector Company, Italy}

\subsubsection{Jenway PFP7 Flame Photometer}

The PFP7 operates with liquefied petroleum gas (LPG) and supplied with $\mathrm{Na}, \mathrm{K}, \mathrm{Ba}, \mathrm{Ca}$ and $\mathrm{Li}$ filters. Before use, calibration with a series of standard $\mathrm{NaCl}$ solutions was done.

\section{Results and Discussions}

\subsection{Water Absorbing Capacity (WAC)}

Results shows that this hydrogel belong to the superabsorbent hydrogels, since it absorbs 58 times its original weight.

\subsection{FTIR Results}

Fig. (2) shows the FTIR spectra for the starting materials (CMC and starch) and the cross-linked CMC/starch blend .

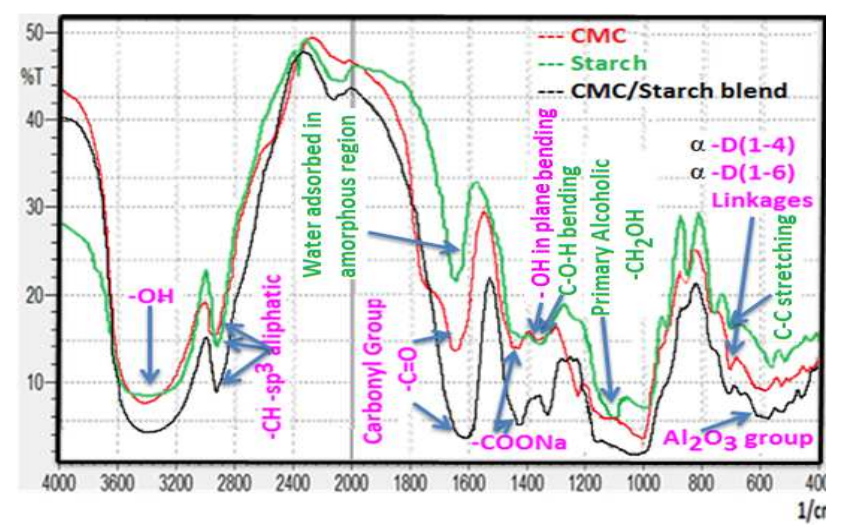

Fig. (2). FTIR spectra of $C M C$, starch, and $C M C /$ starch blend

The CMC spectrum(Figure 2) proves that the sample is CMC because it has a fingerprint region for CMC bands. Mario et al., have found the carboxyl groups and its salts appear at wave numbers of $1600-1640 \mathrm{~cm}^{-1}$ and $1400-1450$ $\mathrm{cm}^{-1}$ respectively[11]. The band at $1030 \mathrm{~cm}^{-1}$ is due to carboxymethyl ether group $>\mathrm{CH} \mathrm{O} \mathrm{CH2-stretching} \mathrm{.}$

The presence of strong absorption band at $1605 \mathrm{~cm}^{-}$ ${ }^{1}$ confirms the presence of $\mathrm{C}=\mathrm{Ogroup}$ (indicated CMC), where absorption band associated with $\mathrm{C}=\mathrm{O}$ bond stretching are usually very strong because a large change in the dipole takes place in that model. Band at $1111 \mathrm{~cm}^{-1}$ belong to the $-\mathrm{C}-\mathrm{O}-\mathrm{C}$ asymmetry bridge stretching [12].

Weak bands at around $770 \mathrm{~cm}^{-1}$ are due to ring stretching and ring deformation of $\alpha$-D-(1-4) and $\alpha$-D-(1-6) linkages respectively. The band at $2924 \mathrm{~cm}^{-1}$ is due to $\mathrm{C}-\mathrm{H}$ stretching of the $-\mathrm{CH}_{2}$ and $\mathrm{CH}_{3}$ groups[13].

The band around $1320 \mathrm{~cm}^{-1}$ is assigned to $\mathrm{OH}$ bending vibration. Broad absorption band at $3200-3600 \mathrm{~cm}^{-1}$, due to the stretching frequency of the $-\mathrm{OH}$ group [7] .

Starch spectrum shows C-C stretching at $764 \mathrm{~cm}^{-1}$, skeletal mode vibrations of $\alpha-1,4$,glycosidic linkage (C-O-C) at $930 \mathrm{~cm}^{-1}$, primary alcoholic $-\mathrm{CH}_{2} \mathrm{OH}$ stretching mode at $1078 \mathrm{~cm}^{-1}, \mathrm{C}-\mathrm{O}-\mathrm{H}$ bending at $1094 \mathrm{~cm}^{-1}, \mathrm{C}-\mathrm{O}$ stretching at $1163 \mathrm{~cm}^{-1}, \mathrm{CH}_{2}$ bending at $1415 \mathrm{~cm}^{-1}$, water adsorbed in the amorphous regions of starch at $1642 \mathrm{~cm}^{-1}, \mathrm{O}-\mathrm{H}$ stretching at $3000-3600 \mathrm{~cm}^{-1}[14]$.

\subsection{Investigation of Cross-Linking}

Many evidences of the occurrence of the cross-linking process were obtained through this study. Those evidences provided by FTIR, morphology, and absorbency results. 


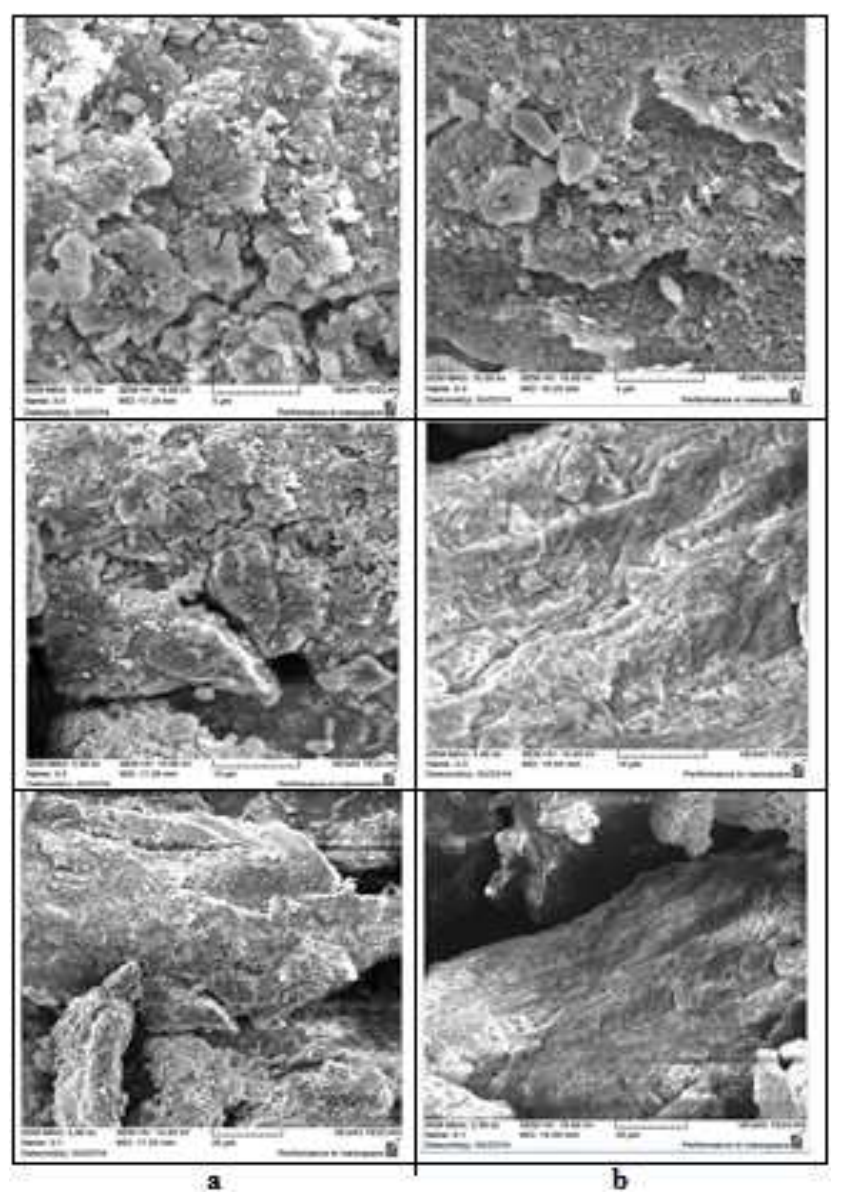

Fig.(3). Surface morphologies of CMC/starch blend with different magnifications (a) before (b) after cross-linking with $\mathrm{Al}_{2}\left(\mathrm{SO}_{4}\right)_{3} .18 \mathrm{H}_{2} \mathrm{O}$

In the $\mathrm{CMC} /$ starch blend spectrum, the absence of the starch primary alcoholic band indicates that this site is active and the reaction between the starch molecule and the CMC molecule occurs through this site [15]. Also, the appearance of the $-\mathrm{COONa}$ and $\mathrm{C}=\mathrm{O}$ groups refer to the efficiency of the blending process. Broadening band at $2900-3600 \mathrm{~cm}^{-1}$ is due to the huge amount of $-\mathrm{OH}$ groups in the blend from both starting materials( CMC and starch).

From morphologies studies, as seen in Figure 3, it seen that there is a different general structures. It is clear the sample after crosslinking ismore compact than before as well as show one piece for after cross-linking comparing with different pieces before cross-linking. This is due to binding the CMC molecules by the cross-linker aluminum sulfate octadecahydrate especially there are three CMC molecules connected to one atom of aluminum, so that the space between molecules before cross-linking disappear after that, i.e. more compact molecule.

\subsection{Evaluation of Blend Miscibility}

Since thatdifferential scanning calorimetry (DSC) used for discrimination between miscible and immiscible polymer blends(where one $T_{\mathrm{g}}$ indicates a miscible system, while two $T_{\mathrm{g}^{\prime}} \mathrm{S}$ indicate an immiscible blend, and the two $T_{\mathrm{g}}$ shifted to the direction of their average is typical of partially miscible systems) [16], it can be concluded from Figure 4 that $\mathrm{CMC} /$ starch is a miscible blend.

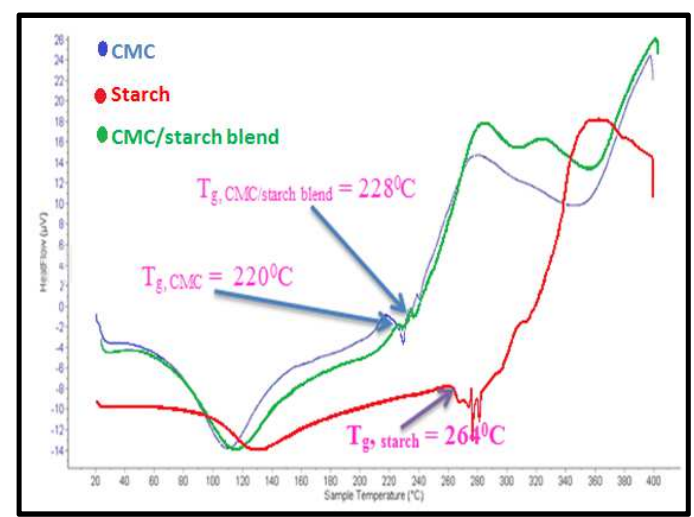

Fig.(4). DSC curves for CMC, starch, and the CMC/starch blend

\subsection{Optimum Cross-Linking Ratio}

The effect of the amount of aluminum sulfate octadecahydrate, which was used as the cross-linker in the polymerization, was studied and the result was shown in Figure 5. The max. of absorbency ( $58 \mathrm{~g} / \mathrm{g}$ in distilled water) was at $2 \%$ of aluminum sulfate octadecahydrate. Above and lower this percent the degree of water absorbency decreases .

According to Floy' theory, increasing cross-linker could increase the nodes of network and the cross-linker density, which is favorable to the super-absorbent absorbing and retaining fluid [17].

Low concentration of the cross-linker leads to low degree of cross linking, and it is hard for network structure to form, so the water absorbency is low. However, when it is higher than the best value, there are more cross-linking points and the pores become smaller in the network, which causes the macroscopic decrease of the absorbency[18].

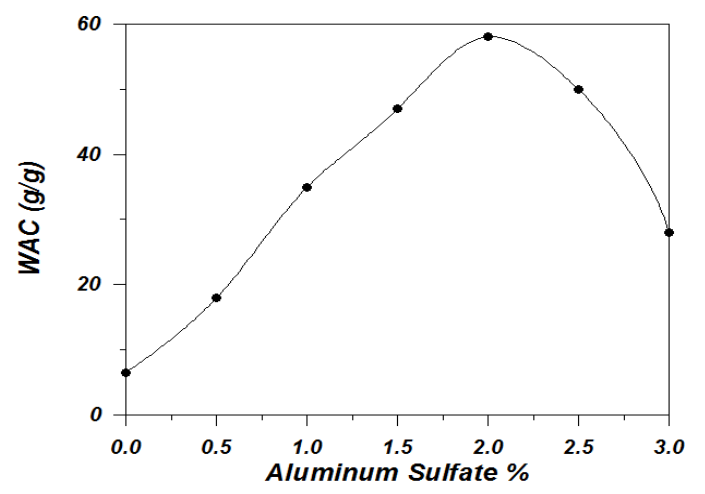

Fig. (5).Optimum percent of aluminum sulfate octedecahydrate cross-linker

It was observed that increasing the concentration of the acidic cross-linking agent (such as the aluminum sulfate octadecahydrate) up to a certain limit enhances the swelling properties of CMC hydrogel. Cross-linker concentration higher than this limit decreases significantly the swelling of the hydrogel. This could be ascribed to decrease flexibility of the chains and the ability of the chains to undergo segmental motion. Diffusion of the hydrolyzing agents (water) into the 
polymer network also decreases thereby giving rise to more rigid structure of the polymer Network [7].

\subsection{Proposed Cross-Linking Model}

In order to suggest a reasonable cross-linking mechanism, some tests and investigations have been done to follow the reactions between the cross-linker and the starting components (CMC and starch).

\subsubsection{Determination of Chemical Formula of CMC}

By using standard sodium chloride solution, three standard concentrations $(37.5,75$, and $150 \mathrm{ppm})$ of sodium chloride $(\mathrm{NaCl})$ is studied using emission spectrum technology, JENWAY pfp7 Flame Photometer (see Figure 6)

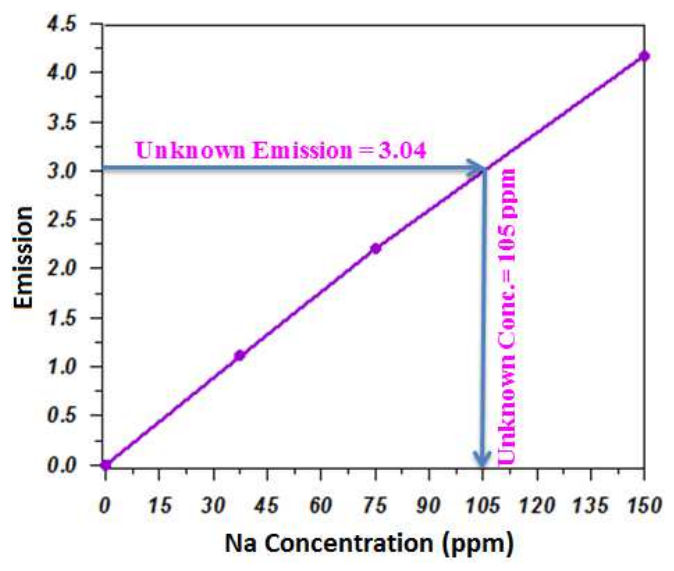

Fig.(6). calibration curve for $\mathrm{Na}$

Unknown solution of $0.1 \mathrm{~g} \mathrm{CMC} \mathrm{in} 100 \mathrm{ml}$ distilled water used to check the number of sodium acetate group, which $105 \mathrm{ppm}$ of sodium. From this concentration calculation shows the presence of two acetate groups.

Theoretically, the concentration of the sodium in the unknown solution assuming there are two sodium acetate groups in the CMC molecule can be calculated as:

$\begin{array}{cc}\text { Weight of } \mathrm{CMC} / \mathrm{g} & \text { Weight of sodium } / \mathrm{g} \\ 484 & 46 \\ 0.1 & \mathrm{X}\end{array}$

$$
\mathrm{X}=\frac{0.1 \times 46}{484}=0.0095 \mathrm{gNain} 100 \text { mlsolution }=95 \mathrm{ppm}
$$

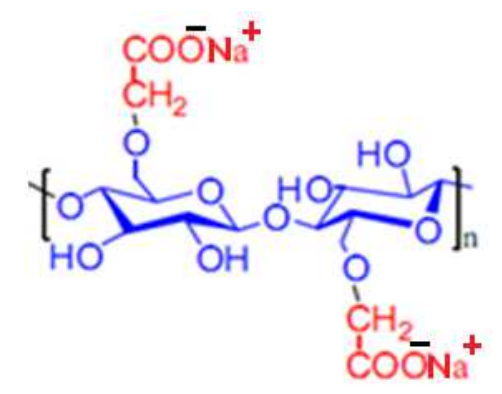

Fig.(7). Chemical structure of the used CMC

Which is in a good agreement with the result obtained practically (105 ppm), thus the used CMC molecule contained two acetate groups with the molecular weight of
$484 \mathrm{~g} / \mathrm{mol}$, i.e., the structure will be as seen in Figure 7.

To confirm that, a CHO test is carried out (using EURO EA Elemental Analyzer). As shown in Table 1 , the CHO results were coincide with the theoretical calculations. The sample may not be completely dry.

Table 1. Elemental chemical analysis of the used CMC

\begin{tabular}{lll}
\hline Element & Theoretically \% & Practically \%[CHO test] \\
\hline $\mathrm{C}$ & 39.669 & 38.985 \\
$\mathrm{H}$ & 4.545 & 4.615 \\
$\mathrm{O}$ & 46.282 & 45.900 \\
$\mathrm{Na}$ & 9.504 & $10.500^{*}$ \\
\hline
\end{tabular}

* Determined by Flame Photometry method

\subsubsection{Investigation of the Active Ion}

When aluminum sulfate octadecahydrate $\left[\mathrm{Al}_{2}\left(\mathrm{SO}_{4}\right)_{3} \cdot 18 \mathrm{H}_{2} \mathrm{O}\right]$ cross-linker dissolve in water, the material dissociates into $2 \mathrm{Al}^{3+}$ and $3 \mathrm{SO}_{4}{ }^{2-}$. It is necessary to investigate which of these ions enters the cross-linking reaction .

To answer the above question, the following procedure have been adopted:

1 Pieces of the cross-linked $\mathrm{CMC} /$ starch blend immersed in hot water $70^{\circ} \mathrm{C}$ for 30 minutes and then filtered. The extraction then divided into two parts.

2 The first part is tested for sulfate group using $\mathrm{BaCl}_{2}$ solution, shows dense white precipitate; i.e. that the sulfate group not share for blend formation.

3 The second part is tested for $\mathrm{Al}^{3+}$ ion using $\mathrm{NaOH}$ solution, shows the absence of $\mathrm{Al}^{+3}$ ion, which indicates that the $\mathrm{Al}^{3+}$ ion share in the blend structure.

4 To confirm this conclusion, test was carried out with platinum wire test on sodium flame shows high $\mathrm{Na}$ emission energy ( 5.75 compared with 0.0 to the distilled water), which indicates that there is an exchange between $\mathrm{Al}$ and $\mathrm{Na}$ ions.

5 To check that aluminum is a part of the structure or not, sample $(1.5523 \mathrm{~g})$ of the cross-linked CMC ignited to $800^{\circ} \mathrm{C}$ for 2 hours in which all hydrocarbons converted to $\mathrm{CO}_{2}$ and $\mathrm{H}_{2} \mathrm{O}$, while $\mathrm{Al}$ changes to oxide if it present. A white precipitate appear $(0.1684 \mathrm{~g})$ for aluminum oxide $\left(\mathrm{Al}_{2} \mathrm{O}_{3}\right)$ and this test confirms the presence of $\mathrm{Al}$.

The amount of $\mathrm{Al}$ in this $\mathrm{Al}_{2} \mathrm{O}_{3}$ precipitate can be calculated as follows:

Weight of $\mathrm{Al}_{2} \mathrm{O}_{3} / \mathrm{g}$
102

Weight ofAl /g

0.1684 54

$$
\mathrm{X}=\frac{0.1684 \times 54}{102}=0.0891 \mathrm{gofAl}
$$

and from Na platinum wire test shows that the presence of $\mathrm{Na}$ ion in the solution of the blend which indicates that $\mathrm{Al}$ substitute $\mathrm{Na}$ in the blend.

The $\mathrm{Al} \%$ in this cross-linked CMC structure can be calculated as follows:

$$
\mathrm{Al} \%=\frac{\text { weightof Al }}{\text { weightofstrucure }}=\frac{0.0891 \mathrm{~g}}{1.5523 \mathrm{~g}} \times 100 \%=5.739 \%
$$


Since that the $\mathrm{Al}$ ion is a trivalent, three $\mathrm{CMC}$ molecules can connect to this ion to form the cross-linked CMC ( molecular weight of the mer is $1443 \mathrm{~g} / \mathrm{mol}$ for the repeating unit) as shown in Figure 8.

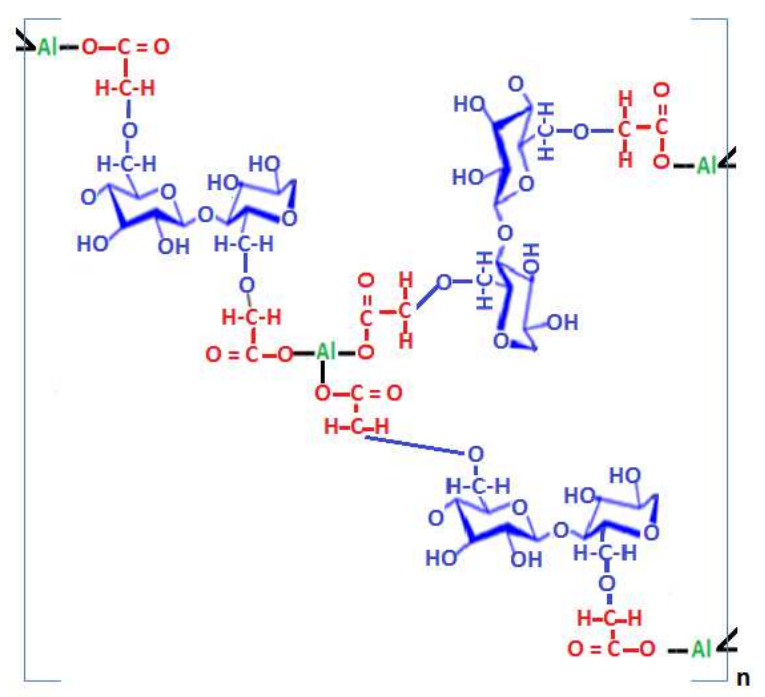

Fig. (8).Proposed cross-linking mechanism between $\mathrm{Al}$ ion and CMC molecules

Theoretically, the $\mathrm{Al} \%$ of this structure can be calculated as follows:

$$
\mathrm{Al} \%=\frac{\text { Atomicweightof } A l}{\begin{array}{c}
\text { Molecularweightof } \\
\frac{3 X 27}{1443} \times 10 \text { - }- \text { linkedCMC }
\end{array} \times 100=5.613 \%}=
$$

Which is in a good agreement with the practical $\mathrm{Al} \%$ value; $5.739 \%$ as shown in Table 2.

Table 2. Elemental chemical analysis of the cross-linked CMC

\begin{tabular}{lll}
\hline Element & Theoretically \% & Practically \%[CHO test] \\
\hline $\mathrm{C}$ & 39.916 & 39.275 \\
$\mathrm{H}$ & 4.573 & 4.470 \\
$\mathrm{O}$ & 49.898 & 50.516 \\
$\mathrm{Al}$ & 5.613 & $5.739 *$ \\
\hline
\end{tabular}

* Determined by ignition method

The following calculation confirms that this structure contains three $\mathrm{Al}$ atoms:

$$
\begin{array}{cc}
\begin{array}{c}
\text { Weight of cross-linked } \mathrm{CMC} / \mathrm{g} \\
1.5523
\end{array} & \begin{array}{c}
\text { Weight of } \mathrm{Al} / \mathrm{g} \\
1443
\end{array} \\
\mathrm{X} & \mathrm{X} \\
\mathrm{X}=82.82 \mathrm{Al} \text {.No. of } \mathrm{Al} \text { atoms }=\frac{\text { Amountof } \mathrm{Al}}{\text { Atomicweightof } \mathrm{Al}} & =\frac{82.82}{27}=3.06 \\
\text { atoms } &
\end{array}
$$

\subsubsection{Cross-Linked CMC/Starch Blend}

FTIR spectrum for the cross-linked $\mathrm{CMC} /$ starch blend (Figure 3) showed the absence of the hydroxy primary alcoholic group in the starch molecule at $1078 \mathrm{~cm}^{-1}$.This indicates that the link between starch and CMC molecules occurs at this site, which can be attributed to lowest space hindrance at this site. This means the new repeating unit contains three additional starch molecules; the molecular weight is $1875 \mathrm{~g} / \mathrm{mol}$ of the mer.(Figure 9)

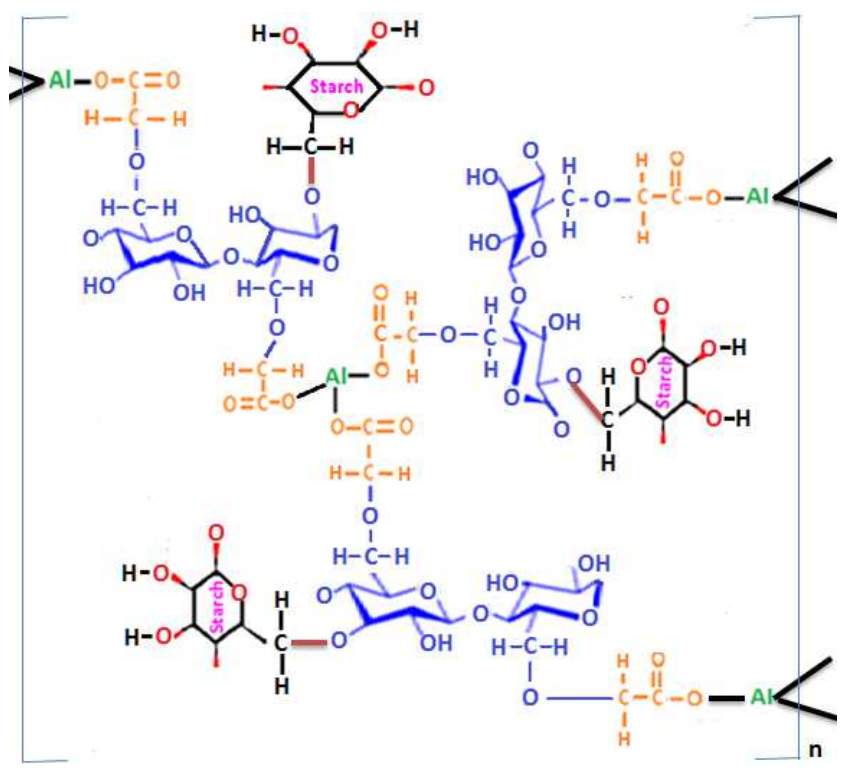

Fig.(9).Proposed cross-linking mechanism model for the Al/ CMC / starch blend

Table 3. EDX test for the cross-linked CMC/starch blend

\begin{tabular}{llllll}
\hline $\begin{array}{l}\text { Eleme } \\
\text { nt }\end{array}$ & $\begin{array}{l}\text { AppCo } \\
\text { nc. }\end{array}$ & $\begin{array}{l}\text { IntensityCo } \\
\text { rr. }\end{array}$ & $\begin{array}{l}\text { Weight } \\
\mathbf{\%}\end{array}$ & $\begin{array}{l}\text { Weight\%Sig } \\
\text { ma }\end{array}$ & $\begin{array}{l}\text { Atomic } \\
\text { \% }\end{array}$ \\
\hline C K & 27.71 & 0.4154 & 43.06 & 1.93 & 46.5 \\
O K & 31.51 & 0.3664 & 55.50 & 1.91 & 48.86 \\
Al K & 1.79 & 0.7985 & 1.45 & 0.28 & 4.64 \\
Total & & & 100.00 & & \\
\hline
\end{tabular}

To confirm this chemical structure, in addition to the EDX results ( Table 3 and figure 10), a comparison between the practical $\mathrm{CHO}$ test results and their theoretical calculations was done (Table 4). Therefore, sample $(1.921 \mathrm{~g})$ of the cross-linked $\mathrm{Al} / \mathrm{CMC} /$ starch blend ignited at $800^{\circ} \mathrm{C}$ for 2 hours. A white precipitate appear $(0.1615 \mathrm{~g})$ for aluminum oxide $\left(\mathrm{Al}_{2} \mathrm{O}_{3}\right)$.

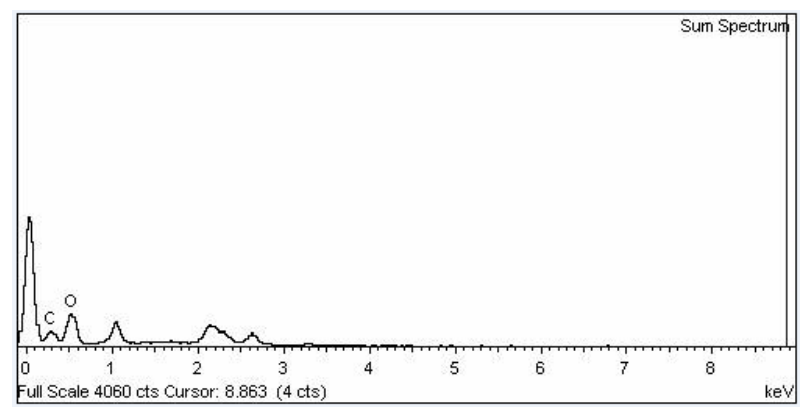

Fig.(10). EDX spectrum for the cross-linked CMC/starch blend

Table 4. Elemental chemical analysis of the cross-linked CMC/ starch blend

\begin{tabular}{lll}
\hline Element & Theoretically \% & Practically \%[CHO test] \\
\hline $\mathrm{C}$ & 42.240 & 41.635 \\
$\mathrm{H}$ & 4.960 & 4.875 \\
$\mathrm{O}$ & 48.480 & 48.978 \\
$\mathrm{Al}$ & 4.320 & $4.512 *$ \\
\hline
\end{tabular}

* Determined by ignition method 
Also, the following calculation confirms that this new chemical structure (for the cross-linked $\mathrm{CMC} /$ starch blend) contains three $\mathrm{Al}$ atoms:

$$
\begin{array}{cc}
\text { Weight of } \mathrm{Al}_{2} \mathrm{O}_{3} & \text { Weight of } \mathrm{Al} \\
102 & 54 \\
0.1615 & \mathrm{X}
\end{array}
$$

$$
\mathrm{X}=\frac{0.1615 \times 54}{102}=0.0855 \mathrm{gofAl}
$$

$$
\begin{array}{cc}
\text { Weight of CMC/starch blend } & \text { Weight of } \mathrm{Al} \\
1.921 \mathrm{~g} & 0.0855 \mathrm{~g} \\
1875 & \mathrm{X} \\
\mathrm{X}=\frac{0.0855 \times 1875}{1.921}=83.452 \mathrm{~g} / \text { molof } \mathrm{Al}
\end{array}
$$

No. of Al atoms $=\frac{\text { Amountof } A l}{\text { Atomicweightof } A l}=\frac{83.452}{27}=3.0908$ atoms

In a very good agreement with three atoms aluminum in the repeating units(mers).

\section{Conclusions}

Theaim of thiswork is to prepare an organometallic compound from $\mathrm{CMC} / \mathrm{starch} /$ Alum is proposal to get high porous structure( high water absorbance capacity).

1 Tests and theoretical calculations confirm that the start material is disodium carboxymethyl cellulose salt.

2 Aluminum ion from Alum (cross-linker) substitutes sodium ion in the starting material.

3 Several tests are carried on to confirm the presence of cross-linker compound.

4 The prepared cross-linked compound shows high porous character.

5 The prepared cross-linked compound shows highly water absorbency capacity reaches $58 \mathrm{~g}$ water/g sample.

\section{References}

[1] V. Mechtcherine , H-W. Reinhardt" Application of Superabsorbent Polymers (SAP) in Concrete Construction" springer, New York ,2012.

[2] C. Nystrand" Feasibility of lignocellulose as feedstock for biological production of superabsorbent polymers" Master Thesis, Linkoping University, 2010

[3] M. Sadeghi, F. Soleimani" Synthesis and Characterization of Superabsorbent Hydrogels for Oral Drug Delivery Systems" International Journal of Chemical Engineering and Applications, Vol.2, No.5, October 2011
[4] P.K. Chatterjee, B.S. Gupta " Absorbent Technology" Elsevier, USA, 2002

[5] G. F. John" Towards Improved Application of Super Absorbent Polymers in Agriculture and Hydrology: A CrossDisciplinary Approach" MSc Thesis, Auburn University, 2011.

[6] M. Elliot "Superabsorbent Polymers" BASF, 2010.

[7] M. Hashem, S. Sharaf, M.M. Abd El-Hady, A. Hebeish "Synthesis and characterization of novel carboxymethyl cellulose hydrogels and carboxymethylcellulose-hydrogelZnO-nanocomposites " Carbohydrate Polymers 95 (2013) $421-427$

[8] Buchholz and Peppas "Superabsorbent Polymers" ACS Symposium Series, 1994.

[9] F. L. Buchholz and A. T. Graham" Modern Superabsorbent Polymer Technology" Wiley-VCH, 1997.

[10] S. Jockusch, N. J. Turro, Y. Mitsukami, M. Matsumoto, T. Iwamura, T. Lindner, A. Flohr, G. Massimo" Photoinduced Surface Cross-linking of Superabsorbent Polymer Particles" Journal of Applied Polymer Science, Vol. 111,2163-2170, 2009

[11] P. Mario, , D.W. Adinugrada, M. Haryadi, 2005. Synthesis and characterization of sodium carboxylmethyl cellulose from Cavendish banana pseudo stem (Musa cavendishii LAMBERT). Carbohydr. Polym., 62: 164-169.

[12] G. S. Hutomo, D. W. Marseno, S.Anggrahini and Supriyanto "Synthesis and characterization of sodium carboxymethyl cellulose from pod husk of Cacao (Theobroma cacao L.) " African Journal of Food Science Vol. 6(6), pp. 180-185, 31 March, 2012.

[13] J. Wang, P. Somasundaran" Adsorption and conformation of carboxymethyl cellulose at solid-liquid interfaces using spectroscopic, AFM and allied techniques" Journal of Colloid and Interface Science 291 (2005) 75-83.

[14] R. Kizil, J. Irudayaraj, and K. Seetharaman"Characterization of Irradiated Starches by Using FT-Raman and FTIR Spectroscopy, 2011.

[15] Jaleel K. Ahmed" Cross-linking Condensation Polymerization of Rayon Fiber" National Journal of Chemistry Vol.26,2007, pp 270-283.

[16] Herman F. Mark" Encyclopedia of Polymer Science and Technology" Third edition, 2005.

[17] A. Pourjavadi, , G.R. Mahdavinia, , 2006. Superabsorbency, $\mathrm{pH}$-sensitivity and swelling kinetics of partially hydrolyzed chitosan-g-poly (acrylamide) hydrogels. Turk. J. Chem. 30, 595-608.]

[18] Z. Ma, Q. Li, Q. Yue, B. Gao, X. Xu, Q. Zhong"Synthesis and characterization of a novel super-absorbent based on wheatstraw" Bioresource Technology 102(2011) 2853-2858. 